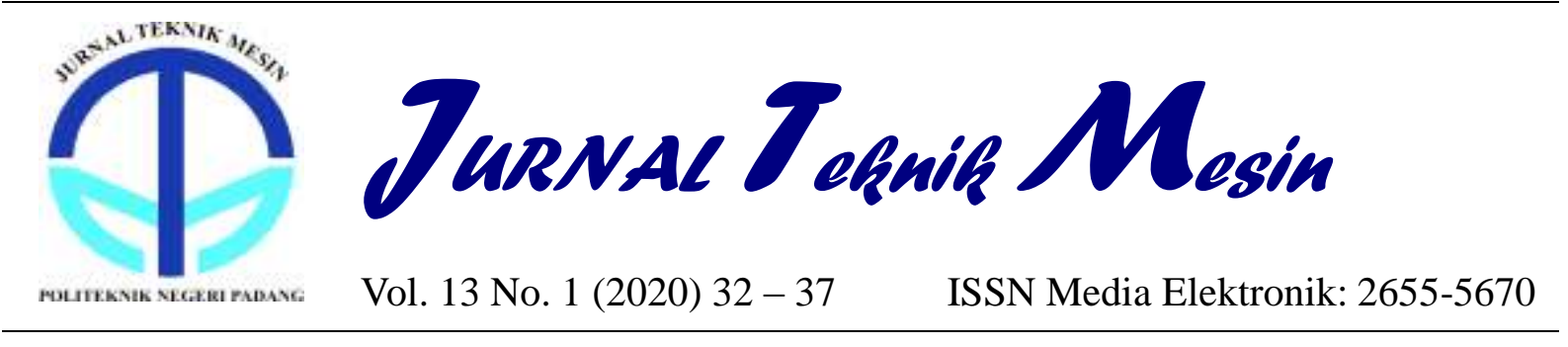

\title{
Optimalisasi Sistem Perawatan dan Perbaikan Mesin Vertical Mill di PT. Semen Padang
}

\author{
Wahmin Rais ${ }^{1 *}$, Afrizul Evendi ${ }^{2}$, Adriansyah ${ }^{3}$, Darman Dapersal Dinar ${ }^{4}$ \\ ${ }^{1}$ Prodi Teknik Manufaktur, Teknik Mesin, Politeknik Negeri Padang \\ ${ }^{2}{ }^{4}$ Prodi D3 Teknik Mesin, Teknik Mesin, Politeknik Negeri Padang \\ *Raisxsmartchommunity@gmail.com
}

\begin{abstract}
Vertical Mill is one of the main equipment in the Indarung IV factory PT. Semen Padang. This Vertical Mill is used to grind / crush the main ingredients of making cement such as Limestone, Silica stone, Clay, and Iron sand. Milling of this material is done with the help of a tool called a Roller Tire and grinding table. So that the Tire Tire and grinding table always work as expected, the Roller Tire and grinding table must be maintained and repaired continuously and planned. Major damage that is often encountered is the occurrence of wear and tear on the Tire Roller and the grinding roller. Countermeasures by adding meat to the Tire Roller and grinding table using welding. With the maintenance and repairs are well scheduled, then we can avoid the causes of a damage from the beginning.
\end{abstract}

Keywords: Roller tire, Grinding table

\begin{abstract}
Abstrak
Vertical Mill merupakan salah satu peralatan utama yang ada di pabrik Indarung IV PT. Semen Padang. Vertical Mill ini digunakan untuk menggiling / mengancurkan bahan utama pembuatan semen seperti batu kapur, batu silika, tanah liat, dan pasir besi, Penggilingan material ini dilakukan dengan bantuan alat yang disebut dengan Roller tyre dan Grinding table. Agar Roller Tyre dan Grinding table selalu bekerja sesuai dengan yang diharapkan, maka Roller Tyre dan grinding table tersebut harus dilakukan perawatan dan perbaikannya secara continue dan terencana. Kerusakan besar yang sering ditemui adalah terjadinya keausan pada Roller Tyre dan grinding roller tersebut. Penanggulangannya dengan cara penambahan daging pada Roller Tyre dan grinding table dengan memakai las. Dengan adanya perawatan dan perbaikan yang terjadwal dengan baik, maka kita dapat menghindari penyebab-penyebab suatu kerusakan dari awal.
\end{abstract}

Kata Kunci : Roller tyre, Grinding table

\section{Pendahuluan}

Di era globalisasi saat ini dengan pesatnya perkembangan teknologi memacu tumbuh pesatnya perkembangan industri. Seiring hal tersebut menyebabkan terciptanya dunia kerja yang membutuhkan tenaga kerja yang terampil, profesional dan berpengetahuan yang luas dibidangnya masing-masing. Pertumbuhan dunia industri tidak terlepas dari dukungan peralatan-peralatan canggih yang sangat membantu aktivitas produksi industri tersebut.

Dalam dunia perindustrian mesin vertikal mill umumnya digunakan pada proses penggilingan material. Khusus di PT. Semen Padang mesin vertikal mill digunakan untuk menggiling material seperti : (campuran lime stone, silica stone, clay dan iron sand). Mesin vertikal mill merupakan mesin yang sangat penting dalam kelancaran aktifitas di industri khususnya di PT. Semen Padang sehingga memungkinkan terjadinya kerusakan-kerusakan yang berat bisa saja terjadi. Untuk mengendalikan mesin vertikal mill tersebut ke seperti semula dan mencegah kerusakan seperti kerusakan pada Grinding roller,Table liner, Grinding table, Dambring, Louvre ring, Mill stand and mill body, Rocker arm and hydrolic spiring system, Clasifier oleh karna itu perlu diadakan tindakan perawatan dan perbaikan.

Oleh karena itu, perawatan dan perbaikan pada Mesin vertikal mill sangat penting sekali dalam penentuan umur mesin itu sendiri. Apabila tidak dirawat dengan baik dan tidak menurut ketentuan dari mesin tersebut, maka mesin ini akan cepat mengalami kerusakan seperti yang dikemukakan di atas.. 
Dengan diadakannya tindakan perawatan dan perbaikan seperti di atas maka diharapkan bahwa kerusakan-kerusakan pada mesin vertikal mill bisa dikurangi, oleh sebab itu penulis mencoba mengulas kembali cara perawatan dan memberikan metode peraw atan yang lebih efisien. Karena mesin vertikal mill tersebut sangat vital fungsinya pada proses pembuatan semen, maka mesin tersebut harus dilakukan perawatan dengan baik. Begitu pula bila mesin tersebut mengalami kerusakan, maka harus dilakukan perbaikan.

\section{Metode Penelitian}

Adapun langkah langkah dalam perawatan dan perbaikan mesin Vertikal mill yaitu : Mulai, Studi literatur, Tindakan perawatan dan perbaikan, Pemeriksaan kondisi akhir, sampai selesai, sehinggga mesin dapat berfungsi dengan baik dan bekerja dengan optimal. Untuk lebih jelas diagram alir kerjanya dapat dilihat pada Gambar 1 .

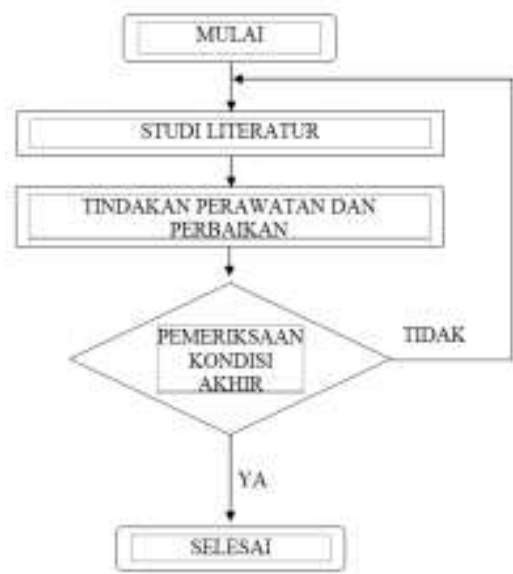

Gambar 1. Skema Perawatan dan perbaikan

\section{Alat dan Bahan}

Alat-alat yang dipakai adalah Mesin vertikal mill, Mesin las, Blender potong. Sedangkan bahan yang diperlukan adalah Elektoda las, Gomok dan Oil pelumas. Untuk lebih jelasnya tentang mesin vertikal dapat dilihat pada Gambar 2.

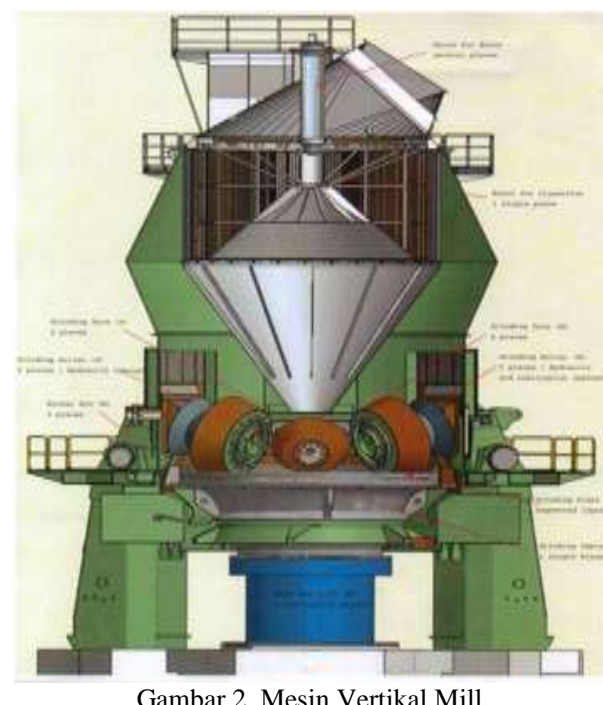

\section{Hasil dan Pembahasan}

\subsection{Mesin Vertikal mill}

Mesin Vertikal mill merupakan suatu peralatan yang berfungsi sebagai penggiling semen dengan tipe vertikal, diamana metode penggilingan menggunakan roller dan table dengan tekanan tinggi serta terinstalasi separator didalamnya untuk proses separasi. Di dalam mesin ini material mengalami proses penghalusan ukuran butiran sehingga menghasilkan tepung baku (raw meal)[9]

Vertikal mill berfungsi untuk menggiling material kerja yang masuk dalam ruangan penggiling hal ini digunakan untuk menggiling (campuran lime stone, silica stone, clay dan iron sand) agar dihasilkan rawmix untuk selanjutnya dimasukkan ke dalam kiln[1,2]. Pada mesin vertikal mill terdapat beberapa komponen utama, yaitu:Grinding table, Grinding roller, Rocker arm dan hydrolic spiring system, Table linear, Damring, Mill stand and milll body, Classifier, Lauvre ring[6].

\subsection{Perawatan Dan Perbaikan Mesin Vertikal Mill}

Perawatan dan perbaikan adalah suatu tindakan untuk menjaga atau memperbaiki kondisi mesin sampai pada suatu kondisi yang dapat diterima[3]. Semua tindakan perawatan bertujuan menghindarkan atau menghambat kerusakan, atau mengetahui terjadinya kerusakan sebelum terjadi gangguan [7]. Tindakan perawatan dan perbaikan pada Mesin vertikal mill lebih diutamakan agar dapat berjalan dengan semestinya, karena tiap komponen merupakan suatu kesatuan yang saling berhubungan. Bila suatu komponen mengalami kerusakan akan mempengaruhi kinerja peralatan atau mesin dan berpengaruh juga terhadap komponenkomponen lainnya.

Untuk menghindari tingginya biaya yang dibutuhkan untuk mengganti kerusakan komponen utama pada Mesin vertikal mill apabila terjadi kerusakan yang fatal dan biaya operasional yang hilang karena adanya waktu untuk memperbaiki peralatan atau mesin tersebut, maka langkah yang perlu diambil adalah melakukan serangkaian tindakan perawatan dan perbaikan pada Mesin vertikal mill tersebut terutama pada komponen-komponen utamanya

\section{Perawatan Komponen-Komponen Utama Mesin Vertikal Mill}

Pekerjaan perawatan harus mulai dilakukan sejak awal dan kita harus menyadari bahwa pekerjaan perawatan itu adalah pekerjaan yang sangat penting dan sangat mendasar dalam suatu mesin, maka pekerjaan itu tidaklah terlalu berat atau sulit. Dengan demikian maka perawatan pada mesin vertikal mill banyak ditujukan pada bagian-bagian atau komponen komponen utama pada mesin ini. Komponen-komponen utama mesin vertikal mill adalah :

\section{Grinding Table}

Grinding table merupakan salah satu komponen yang sangat penting dalam proses penggilingan pada mesin vertikal mill. Kemampuan mesin grinding yang dapat memprosesmaterial sangat penting saat meningkatnya produk yang punya tingkat kekerasan yang tinggi[8]. jadi harus dilakukan 
parawatan dan perbaikan dengan baik supaya tidak mengalami kerusakan yang lebih parah.

Walaupun dengan pemakaian dan proses kerjanya berjalan dengan maksimal sesuai dengan petunjuk, komponen ini juga sering mengalami kerusakan. Beberapa perawatan pada grinding table adalah[4]:

a) Pada saat mesin berhenti maka harus dilakukan pengecekan kehausan pada grinding table.

b) Lakukan pengukuran pada kehausan berapa dalam kehausan dari grinding table tersebut.

Adapun perawatan yang dilakukan pada ring clem table adalah sebagai berikut[5] :

a) Ambil Ring clem table didalam Worshop apabila diperlukan.

b) Untuk mengetahui ada tidaknya gangguan pada Clem dapat dilakukan pemeriksaan apabila mesin dalam keadaan berhenti.

Adapun perawatan yang dilakukan pada baut L 34 adalah sebagai berikut :

a) Pada mesin berhenti maka lakukan pembersihan pada kepala baut supaya bisa mengetahui keadaan dari baut tersebut.

b) Pada saat mesin berhenti lakukan penguncian pada baut yang longgar.

Tyre Roller

Tyre Roller adalah sebuah Adapun prosedur perawatan dari Tryre roller adalah sebagai berikut :

a. Lakukan pengecekan visual, yre roller secara keseluruhan.

b. Bersihkan material yang menempel di tyre roller supaya mudah melihat kehausannya.

c. Periksa kondisi tyre, periksa kehausan pada tyre roller berapa kedalammannya dibagian atas tyre roller.

Adapun cara perawatan komponen yang ada di dalam Tyre roller adalah sebagai berikut[5] :

\section{$\mathrm{Hub}$}

berfungsi untuk kedudukan bearing dalam tyre komponen ini juga sering mengalami kerusakan. Adapun cara perawatannya adalah sebagai berikut :

a. Lakukan pemeriksaan pada hub diwaktu pembersihan.

b. Periksa apakah di dalam hub ada terdapat goresan atau lubang.

c. Apabila di dalam hub kekurangan pelumas maka tambah dengan pelumas yang sama.

\section{Shaft}

Berfungsi untuk kedudukan hub dan kedudukan tyre komponen ini sering mengalami kerusakan. Adapun cara perawatannya adalah sebagai berikut :

a. Lakukanlah pembersihan pada saat pembongkaran

b. Periksa kondisi ulir pada poros shaft.

\section{Seal}

Berfungsi untuk menahan oil dalam bearing roller agar tidak bocor komponen ini juga sering mengalami kurusakan.

\section{Tyre}

berfungsi untuk menggiling matrial yang masuk ke dalam ruangan penggilingan, komponen ini jarang sekali mengalami kerusakan[5].Adapun cara perawatannya adalah sebagai berikut:

a. Lakukan pengecekan secara visual terhadap kehausan pada pada bagian permukaannya.

b. Bersihkan material yang menempel dipermukaannya. Seperti yang terlihat pada Gambar 3.

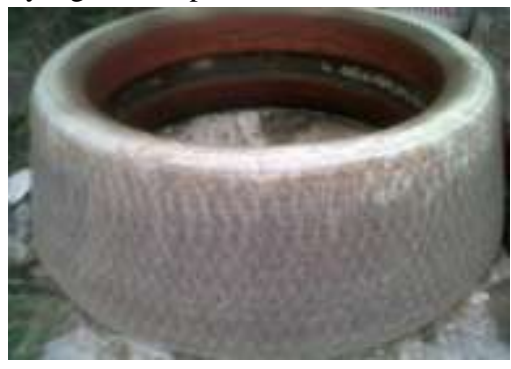

Gambar 3. Tyre

\section{Bearing}

Berfungsi untuk memudahkan putaran tyre pada table. Bearing menjaga poros (shaft) agar selalu berputar terhadap sumbu porosnya dan menjaga suatu komponen yang bergerak linier agar selalu berada pada jalurnya. Untuk perawatan dari bearing tidaklah memerlukan perhatian khusus. Hal ini karena bearing tidak ada komponen yang rumit, jadi pada intinya adalah pemberian pelumas sesuai dengan kerja yang ada[10]. Seperti yang telihat pada Gambar 4.

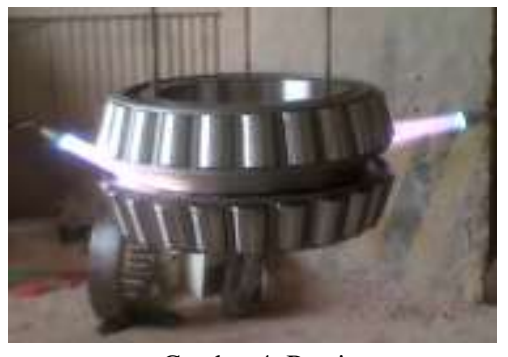

Gambar 4. Bearing

\section{Rocker Arm and Hydrolic Spiring System}

Perawatan pada Rocker arm and hidrolic spiring sistim adalah suatu tindakan yang dilakukan dengan tujuan mempermudah grinding roller dalam penggilingan material walaupun dalam keadaan material itu besar ataupun kecil. Walaupun dengan pemakaian dan proses kerjanya berjalan dengan maksimal sesuai dengan petunjuk, komponen ini juga sering mengalami kerusakan[3]. Beberapa perawatan pada Rocker arm and hydrolic spiring system,yaitu: membersihkan kotoran-kotoran yang menempel pada bodi rocker arm dan hidrolic spiring syste (debu, tanah maupun bekas oli). Adapun cara perawatan komponen yang ada di dalam rocker arm dan hydrolic spiring system adalah sebagai berikut[4] : 


\section{Selang (hose)}

Adapun perawatan yang dilakukan selang adalah sebagai berikut :

a. Jangan pernah menyimpan selang pada tempat yang panas, ruangan lembab, terkena langsung dengan sinar matahari

b. Jangan menumpuk-numpukkan selang, karena berat tumpukan akan membuat rusak selang bagian bawah.

\section{Perbaikan Komponen-Komponen Utama Mesin Vertikal} Mill.

\section{Adanya Beberapa Cekungan Pada Grinding Table.}

Cekungan yang terjadi pada grinding table disebabkan oleh pada saat proses penggilingan material yang masuk ke dalam ruangan penggiling tidak sama besar. Adapun beberapa identifikasi cekungan pada grinding table adalah sebagai berikut :

a. Grinding table masih bisa dipakai, terdapar cekungan pada yang masih kecil pada table yang biasanya karena terdapat material yang besar sehingga menekan table dengan keras.

b. Grinding table harus diperbaiki, cekungan pada grinding table dengan ukuran dalam cekungan 20$30 \mathrm{~mm}$.

c. Grinding table harus diganti, cekungan yang sangat parah dan tidak bisa diperbaiki dengan ukuran cekungan lebih dari $60 \mathrm{~mm}$.

Adapun tindakan/perbaikan pada grinding table adalah sebagai berikut :

a. Pastikan sebelum bekerja terlebih dahulu koordinasi dengan pihak/operator proses produksi.

b. Persiapkan semua peralatan kerja yang akan dipakai dilokasi kerja.

c. Bersihkan grinding table dari material yang masuk ke dalam cekungan.

d. Periksa kedalaman grinding table, dari cekungan.

e. Lakukan pengelasan pada cekungan grinding table sesuai dengan ukuran yang masih bisa dilas. Misalkan ukuran kedalaman $30 \mathrm{~mm}$ maka dilakukan penambahan dengan dilakukan pengelasan.

\section{Adanya Beberapa Goresan Pada Shaft}

Goresan yang terjadi pada dinding shaft disebabkan pada saat akan membuka bust, karna dilakukan dengan cara dipanaskan dan shaft juga memiliki 3 buah baut yang berguna untuk menahan kedudukan saat membuka grinding roller. Seperti yang telihat pada Gambar 5.

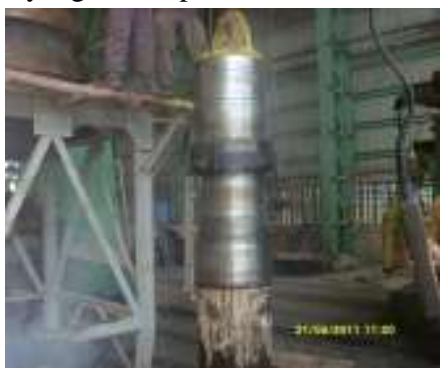

Gambar 5. Goresan pada shaft
Tindakan/perbaikan pada shaft adalah sebagai berikut:

a. Buka bush pada shaft

b. Lihat berapa dalam goresan pada shaft max kurang dari $1 \mathrm{~mm}$

c. Lakukan amplas pada goresan shaft

d. Cek kondisi alur/lubang baut pada posisi atas shaft

e. Lakukan pembersihan pada lubang alur tersebut menggunakan STP

f. Masukan baut pada posisi atas shaft tersebut kalau waktu memutarnya susah maka lakukan tap pada lubang baut tersebut.

\section{Kerusakan Pada Tyre}

Kerusakan pada tyre disebabkan oleh material yang tidak sama besar pada saat akan dilakukan penggilingan. Seperti yang telihat pada Gambar 6.

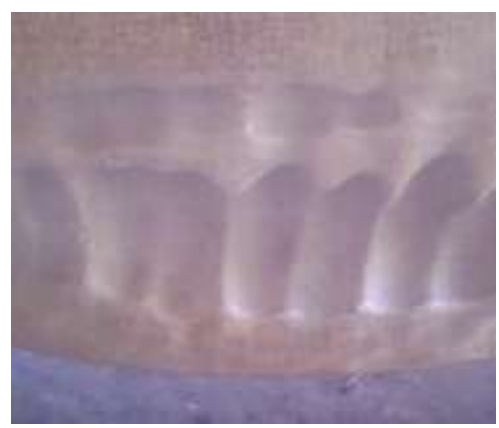

Gambar 6. Tyre Yang Rusak

Tindakan /perbaikan pada tyre adalah sebagai berikut :

a. Gouging (meratakan / membersihkan base metal sebelum pengelasan Welding Alloys dilakukan), seperti yang telihat pada Gambar 7 .

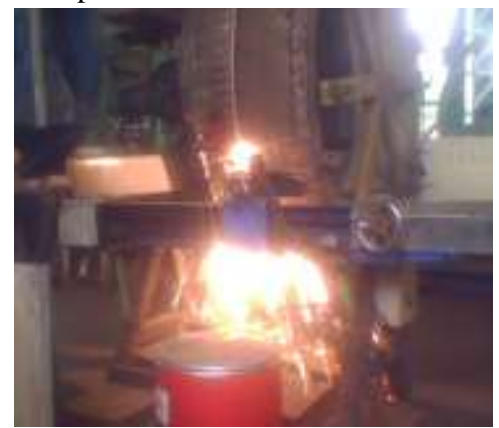

Gambar 7. Proses Gouging roller tyre

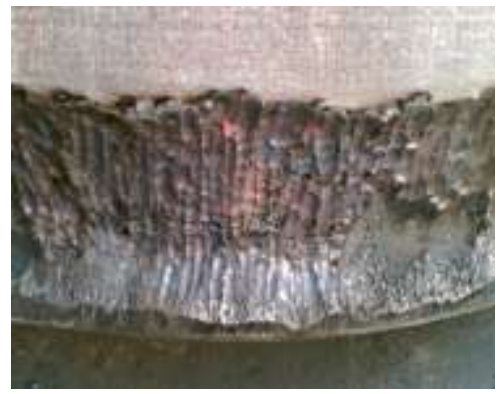

Gambar 8. Hasil Setelah di Gauging 
b. Membersihkan Tyre dengan sikat kawat dengan tujuan agar saat pengelasan Tyre telah bersih dari kerak hasil Gauging tadinya.

c. Menaikan Tyre ke Table mesin Welding Alloys. Seperti yang telihat pada Gambar 9 .

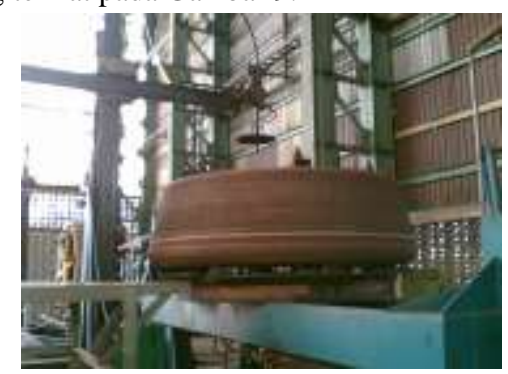

Gambar 9. Tyre Pada Table Mesin Welding Alloys

d. Mendudukkan benda kerja ke Spindel.

e. Memasang skor pengaman pada Tyre tersebut.

f. Memanaskan Tyre dengan api untuk menghilangkan kadar airnya. Seperti yang telihat pada Gambar 10.

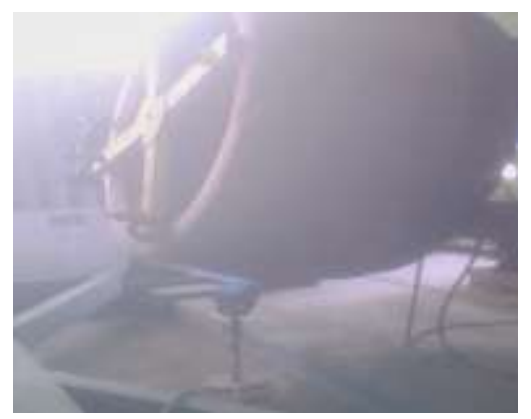

Gambar 10 Tyre Pada Saat Dipanaskan

g. Mengkalibrasi Panel Mesin Welding Alloys,melakukan pengelasan dengan mesin Welding Alloys. Seperti yang telihat pada Gambar 11.

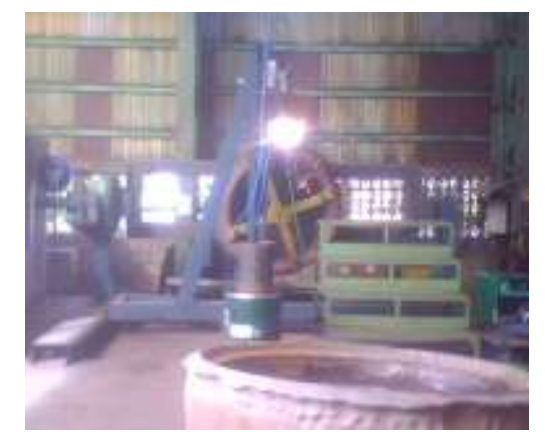

Gambar 11.Tyre Pada Saat Pengelasan

h. Setelah selesai ukurlah Tyre dengan Mall yang telah ditentukan tadi, apabila ukurannya telah pas dengan Mall tersebut, pengelasan selesai dan Tyre siap untuk digunakan lagi di Vertical Mill kembali. Seperti yang telihat pada Gambar 12.

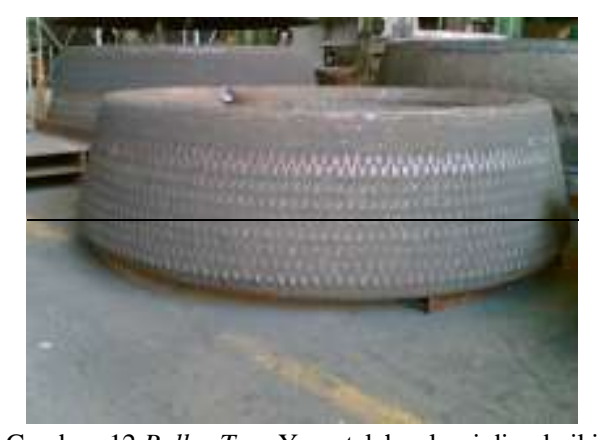

Gambar 12.Roller Tyre Yang telah selesai diperbaiki

\section{Bearing Rusak}

Bearing rusak disebabkan oleh seal yang bocor sehingga tidak bisa menahan oli, untuk melumasi $b$ earing tersebut sehingga bearing mengalami kekurangan pelumas akibatnya terjadi panas yang berlebihan mengakibatkan bearing itu retak dan pecah. Tindakan perbaikannya adalah sebagai berikut :

a. Letakkan shaft pada posisi yang tegak lurus.

b. Asukan inner ring dalam kedalam shaft. Seperti yang telihat pada Gambar 13.

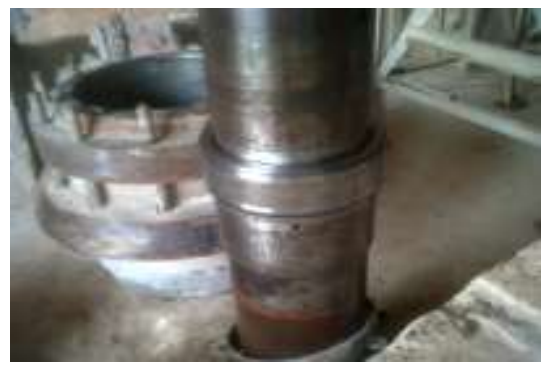

Gambar 13. Inner Ring Yang Terpasang

c. Pasang kaki tiga pada bearing. Seperti yang telihat pada Gambar 14.

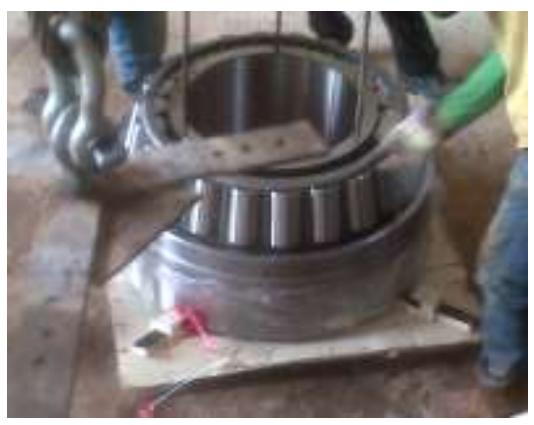

Gambar 14.Pemasangan Kaki Tiga

d. Angkat bearing hingga 1m maka lakukan pemanasan dengan menggunakan blender potong yang ukuran besar.

e. Beri pelumas pada shaft

f. Setelah bearing dipanaskan sampai $40^{\circ} \mathrm{c}$ maka pasangkan pada shaft secara berlahan. Seperti yang telihat pada Gambar 15. 


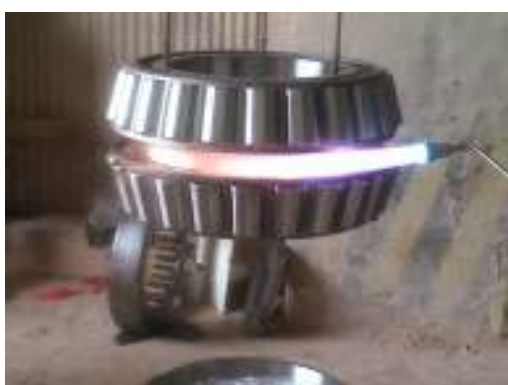

Gambar 15.Bearing Dipanaskan

g. Sampai bearing tertumpu pada inner ring. Seperti yang telihat pada Pada Gambar 16.

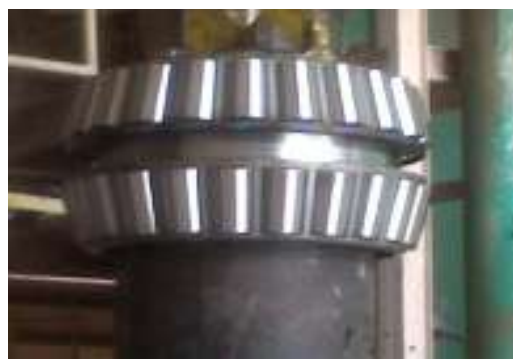

Gambar 16.Bearing Tertumpu Pada Inner Ring

\section{Seal Haus/ Meleleh}

Seal haus/meleleh disebabkan pada waktu panas yang berlebihan pada shaft. Untuk mengatasinya maka dilakukan penggantian seal. Seperti yang terlihat pada Gambar 17 .

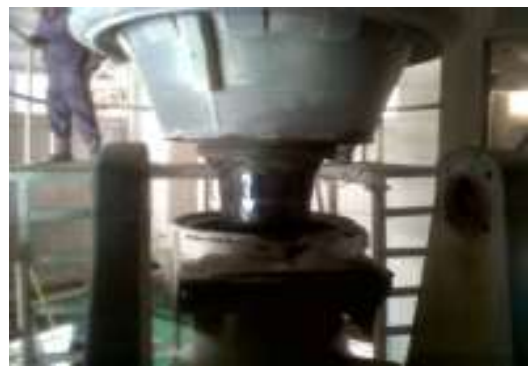

Gambar 17.seal yang bocor

Tindakan perbaikan pada seal adalah sebagai berikut :

a. Buka baut pada seal sebanyak 3 buah

b. Buka ring pada seal yang berguna untuk menahan seal supaya pas

c. Buka dan ganti seal yang bocor

d. Beri pelumas pada shaft

e. Bersihkan kedudukan seal dari debu sebelum dipasang.

f. Masukan seal secara merata lalu kunci ring penahan seal secara bersilangan.

\section{Selang Rusak/Bocor}

Selang rusak diakibatkan oleh fluida yang mengalir di dalam selang memiliki kotoran sehingga kotoran tersebut menyumpat. Untuk mengatasinya maka lakukan pembersihan sebagai berikut :

a. baut clem pada selang bagian atas dan bawah

b. Cuci selang menggunakan minyak/solar

c. Masukan solar kedalam selang

d. Masukan udara ke dalam selang menggunakan kompresor

\section{Kesimpulan}

Kesimpulan yang dapat diambil dari perawatan dan perbaikan mesin vertikal mill di PT.Semen padang, yaitu:

a. Perawatan dan perbaikan yang terjadwal dengan baik, maka kita dapat menghindari penyebab-penyebab suatu kerusakan dari awal

b. Perawatan komponen-komponen utama mesin vertical mill antara lain Grinding table, Tryre roller, Rocker arm dan hidrolic spiring sistim, Selang (hose).

c. Kerusakan yang biasa terjadi pada mesin vertikal mill antara lain adanya beberapa cekungan pada Grinding table, adanya kerusakan pada Shaft, kerusakan pada Tyre, bearing, seal haus/meleleh, selang rusak/bocor.

\section{Daftar Rujukan}

[1] Anonym. 1998. Memperkenalkan Produk-Produk PT. Semen Padang. Edisi 1998. PT. Semen Padang

[2] Santoso, Irwan. 1995. Raw mill. PT. Semen Padang

[3] Hadi,syamsul.2019.Perawatan dan perbaikan mesin industri.Yogyakarta:Penerbit Andi.

[4] Tim Instruktur. 2007.Training Mesin-Mesin Pabrik Departemen Produksi II/III, IV, V. Indarung PT. Semen Padang

[5] Evendi,Afrizul.2014.Tugas Akhir. Perawatan dan Perbaikan Mesin Vertikal Mill di PT Semen Padang. Teknik Mesin: Politeknik Negeri Padang.

[6] Kurniawan,Ryan Tri.2017.Tugas Akhir. Analisis kegagalan komponen spring rod dalam spring suspension assembly pada coal mill tuban I PT.Semen Indonesia TBK. Teknik Industri: Institut Teknologi Sepuluh Nopember.

[7] Widana,I Ketut.2020.Manajemen Perawatan \& Perbaikan di dunia Industri. Teknik Mesin: Politeknik Negeri Bali.

[8] Marinescu,Loan D.2007.Handbook of machining with Grinding Whell. United State of America: Taylor \& Francis Group.

[9] Hidayat,Syarif.2009.Semen:Jenis \& Aplikasinya. Jakarta:Kawan pustaka

[10] Marzuki,2015.Semen:Buku tabel Teknik Mesin:seri:elelemen(material,standart dan aplikasi). Sulawesi Selatan:Gunung Samudra. 